\title{
Spotlight on crizotinib in the first-line treatment of ALK-positive advanced non-small-cell lung cancer: patients selection and perspectives
}

This article was published in the following Dove Press journal:

Lung Cancer:Targets and Therapy

17 June 2016

Number of times this article has been viewed

\author{
Etienne Giroux Leprieur ${ }^{1,2}$ \\ Vincent Fallet ${ }^{3,4}$ \\ Jacques Cadranel ${ }^{3,4}$ \\ Marie Wislez ${ }^{3,4}$ \\ 'Respiratory Diseases and Thoracic \\ Oncology Department, APHP- \\ Ambroise Paré Hospital, Boulogne- \\ Billancourt, France; ${ }^{2}$ EA4340 \\ Laboratory, UVSQ, Paris-Saclay \\ University, France; ${ }^{3}$ Respiratory \\ Diseases Department, APHP - Tenon \\ Hospital, Paris, France; ${ }^{4}$ Sorbonne \\ University, GRC 04, UPMC Univ \\ Paris 06, France
}

\begin{abstract}
Around 4\% of advanced non-small-cell lung cancers (NSCLCs) have an $A L K$ rearrangement at the time of diagnosis. This molecular feature is more frequent in young patients, with no/light smoking habit and with adenocarcinoma pathological subtype. Crizotinib is a tyrosine kinase inhibitor, targeting ALK, ROS1, RON, and MET. The preclinical efficacy results led to a fast-track clinical development. The US Food and Drug Administration (FDA) approval was achieved after the Phase I clinical trial in 2011 in ALK-rearranged advanced NSCLC progressing after a first-line treatment. In 2013, the randomized Phase III trial PROFILE-1007 confirmed the efficacy of crizotinib in ALK-rearranged NSCLC, compared to cytotoxic chemotherapy, in second-line setting or more. In 2014, the PROFILE-1014 trial showed the superiority of crizotinib in the first-line setting compared to the pemetrexed platinum doublet chemotherapy. The response rate was $74 \%$, and the progression-free survival was 10.9 months with crizotinib. Based on these results, crizotinib received approval from the FDA and European Medicines Agency for first-line treatment of ALK-rearranged NSCLC. The various molecular mechanisms at the time of the progression (ALK mutations or amplification, ALK-independent mechanisms) encourage performing re-biopsy at the time of progression under crizotinib. The best treatment strategy at the progression (crizotinib continuation beyond progression, switch to second-generation tyrosine kinase inhibitors, or cytotoxic chemotherapy) depends on the phenotype of the progression, the molecular status, and the physical condition of the patient.
\end{abstract}

Keywords: ALK rearrangement, crizotinib, non-small-cell lung carcinoma

\section{Introduction}

The majority of non-small-cell lung cancers (NSCLCs) are diagnosed at an advanced stage, with a poor prognosis. Until the early 2000s, the first-line treatment was a platinum-based doublet chemotherapy, which was initiated based on the global condition of the patient but without any pathological or molecular selection. The overall survival was poor, $\sim 8$ months, whatever may be the type of cytotoxic chemotherapy given. ${ }^{1}$ In 2008, Scagliotti et al demonstrated that a pathology-based selection led to a differential choice of cytotoxic chemotherapy: non-squamous carcinoma was treated more effectively by a platinum-pemetrexed doublet, whereas squamous cell carcinoma was not. ${ }^{2}$ Since several years, extensive molecular characterization of NSCLC is ongoing. Several oncogenic addiction mechanisms have been described. The presence of mutation of the EGFR gene, occurring in 10\%-15\% of NSCLCs, induces tumor sensitivity to targeted therapies, that is, EGFR tyrosine kinase inhibitors (TKIs), such as erlotinib, gefitinib, and afatinib. ${ }^{3}$ These drugs are currently authorized
Wislez Respiratory Diseases Department, APHP - Tenon Hospital, 4 rue de la Chine, 75970 Paris, France

$\mathrm{Tel}+33$ I $560 \mid 6838$

Fax +33 I 560 I 7248

Email marie.wislez@tnn.aphp.fr 
for first-line treatment of EGFR-mutated advanced-stage NSCLC. Among the other oncogenic addictions, $4 \%$ of NSCLCs harbor an $A L K$ rearrangement. ${ }^{3}$ Specific ALK TKIs have been developed. Crizotinib is a multi-targeted (ALK, ROS, MET, RON) TKI that shows efficacy in the treatment of ALK-rearranged advanced-stage NSCLC. In this review, we describe the molecular characteristics and the phenotype of ALK-rearranged NSCLC, the mechanism of action of crizotinib, and the results of the early development steps and of the clinical trials that led to approval by the US Food and Drug Administration (FDA) and European Medicines Agency (EMA) of crizotinib for first-line treatment of ALKrearranged advanced-stage NSCLC. We also discuss about the patient selection and the molecular mechanisms of tumor progression with crizotinib.

\section{ALK rearrangement in NSCLC}

ALK protein is a membranous receptor with an intracellular tyrosine kinase domain. $A L K$ rearrangements involve the exon 20 coding for the tyrosine domain, inducing the formation of a fusion gene and the constitutive activation of ALK with stimulation of downstream pathways (PI3K, STAT3, JAK2, and Ras pathways). ${ }^{4}$ The companion gene for the rearrangement is most of the time $E M L 4$. Other genes have also been involved, such as $T F G, K I F 5 B$, and $K L C 1$. In NSCLC, $A L K$ rearrangement occurs preferentially in young patients, with no/light smoking habit and lung adenocarcinoma., Tumors with ALK rearrangement tend to have lymph node involvement and brain tropism. ${ }^{6}$ Adenocarcinomas with $A L K$ rearrangement have most of the time a solid or acinar pattern, with cribiform architecture and ring cells, expressing TTF1. Until recently, $A L K$ rearrangement was supposed to be mutually exclusive with other oncogene addiction genes ( $E G F R$, Kras). However, recent reports using large-scale techniques (such as next-generation sequencing) have described NSCLC harboring both $A L K$ rearrangement with other oncogenes, as EGFR mutations. ${ }^{7}$ The diagnosis of $A L K$ rearrangement is made by fluorescence in situ hybridization (FISH). The presence of a split signal in $\geq 15 \%$ of tumor cells (based on an analysis of at least 100 nuclei) is consistent with an $A L K$ translocation. Other screening assays have been recently developed, such as immunohistochemistry (IHC) assay. ALK IHC seems to have a good negative predictive value. ${ }^{8}$ In Europe, the EMA approval does not precise the technique to be used to prove ALK rearrangement. In a routine practice, ALK IHC is used for ALK screening at diagnosis, and positive IHC assays are confirmed by FISH. Besides, negative IHC in patients with high clinicopathological probability of
$A L K$ rearrangement also requires a confirmation by FISH. In US, the FDA approval requires a positive FISH assay, based on the use of a Vysis ALK Break Apart FISH Probe Kit (Abbott Molecular, Lake Bluff, IL, USA). Other techniques, such as reverse transcriptase polymerase chain reaction, also allow the diagnosis of $A L K$ rearrangement, with interesting sensitivity and specificity, and could be considered alternatively for ALK rearrangement diagnosis. ${ }^{9}$

\section{Preclinical activity of crizotinib}

Crizotinib is a multi-targeted TKI that shows activity against not only ALK but also ROS1, RON, and MET. In vitro studies have shown antitumor activity with crizotinib. A large panel of human tumor-derived cell lines ( $n=602$, with 134 NSCLC cell lines) was tested with various experimental antitumor compounds. ${ }^{10}$ Crizotinib had antitumor activity in a subset of cell lines, corresponding to anaplastic large cell lymphoma, NSCLC, and neuroblastoma cell lines. Among the 134 tested NSCLC cell lines, three cell lines had drug sensitivity and harbored an $A L K$ rearrangement confirmed by FISH.

\section{Phase I and II trials: PROFILE-I 00 I and PROFILE-I005}

Kwak et al conducted a Phase I trial (PROFILE-1001), testing crizotinib in advanced-stage NSCLC with $A L K$ rearrangement determined by FISH $(\mathrm{n}=82) .{ }^{11}$ Performance status (PS) score was $0-2$. Most of the patients received crizotinib after at least two lines of treatment. These patients were young (mean age: 52 years), Caucasian (56\%), never smoker (76\%), and had an adenocarcinoma (96\%). The first period of the trial was an escalation-dose phase, with crizotinib given from $50 \mathrm{mg}$ once daily to $300 \mathrm{mg}$ twice daily. The maximumtolerated dose was $250 \mathrm{mg}$ twice daily (limitation due to fatigue). The second period was an expansion phase, where patients received crizotinib at the maximum-tolerated dose (250 mg twice daily). Overall response rate was 57\%, and the estimated 6-month progression-free survival (PFS) was 72\%.

A retrospective analysis of the patients enrolled in this Phase I trial was performed to evaluate the overall survival (OS). ${ }^{12}$ These patients treated with crizotinib were compared with 36 patients with $A L K$-rearranged NSCLC who were not given crizotinib, 67 patients without $A L K$ rearrangement but positive for $E G F R$ mutation, and 253 wild-type patients lacking either $A L K$ rearrangement or $E G F R$ mutation. Median OS of patients treated with crizotinib was not reached, with 1-year OS at $74 \%$ and 2 -year OS at $54 \%$. For patients treated with crizotinib in second- or third line $(\mathrm{n}=30)$, median OS was not reached versus 6 months for patients with $A L K$-rearranged 
Table I Efficacy data of crizotinib in clinical trials

\begin{tabular}{|c|c|c|c|c|}
\hline & PROFILE- $100 \mathrm{I}^{13}$ & PROFILE- $1005^{14}$ & PROFILE- $1007^{15}$ & PROFILE- $1014^{16}$ \\
\hline & $n=143$ & $n=135$ & $n=173$ & $n=172$ \\
\hline Line of treatment & $\geq 2$ & $\geq 2$ & $\geq 2$ & $\mathrm{I}$ \\
\hline Response rate & $60.8 \%$ & $59.8 \%$ & $65.0 \%$ & $74.0 \%$ \\
\hline Duration of response (median) (weeks) & 49.1 & 45.6 & 32.1 & 48.4 \\
\hline PFS (median) (months) & 9.7 & 8.1 & 7.7 & 10.9 \\
\hline \multicolumn{5}{|l|}{ OS } \\
\hline Median (months) & NR & NA & 20.3 & NR \\
\hline I-Year (\%) & 74.8 & NA & NA & 84.0 \\
\hline
\end{tabular}

Abbreviations: PFS, progression-free survival; OS, overall survival; NR, not reached; NA, not available.

NSCLC with other second- or third-line treatment (hazard ratio $[\mathrm{HR}]=0.36,95 \%$ confidence interval $[\mathrm{CI}] 0.17-0.75$, $P=0.004)$. Median OS for patients receiving crizotinib was similar to that of EGFR-mutated patients (24 months, $P=0.786$ ). Median OS for patients with $A L K$-rearranged crizotinib-naive NSCLC was similar to that of wild-type patients ( 20 versus 15 months, $P=0.244$ ).

Updated results of this Phase I trial were published in 2012, based on 143 patients with evaluable tumor response. ${ }^{13}$ Response rate was $60.8 \%$. Median duration of response was 49.1 weeks. Median PFS was 9.7 months, and estimated OS at 6 and 12 months was $87.9 \%$ and $74.8 \%$, respectively (Table 1).

The PROFILE-1005 trial was a multicenter, single-arm, open-label Phase II trial, testing crizotinib in patients with $A L K$-rearranged advanced-stage NSCLC who progressed after one or more treatment lines $(n=136) .{ }^{14}$ PS was $0-3$. Patients with brain metastases were eligible if asymptomatic, or if treated, neurologically stable for at least 2 weeks. Onehundred and thirty-five patients were evaluable for response, with a response rate (primary end point) at 53\%. Median duration of response was 43 weeks, and median PFS was 8.5 months (Table 1).

\section{Phase III trial PROFILE-I007: crizotinib in second or third line}

PROFILE-1007 was a randomized, open-label, Phase III trial, comparing the efficacy of crizotinib to standard chemotherapy in advanced NSCLC, after failure of a platinumbased chemotherapy, with $A L K$ rearrangement (determined by FISH). ${ }^{15}$ Three hundred and forty-seven patients were randomized between crizotinib (250 $\mathrm{mg}$ twice daily) and either pemetrexed $\left(500 \mathrm{mg} / \mathrm{m}^{2}\right.$ intravenously [IV], $\left.\mathrm{d} 1 \mathrm{~d} 21\right)$ or docetaxel $\left(75 \mathrm{mg} / \mathrm{m}^{2} \mathrm{IV}, \mathrm{d} 1 \mathrm{~d} 21\right)$. PS score was 0-2. Patients with stable brain metastases who had been treated previously or were untreated and asymptomatic were eligible.
Crossover was allowed after progression. Primary end point was PFS. PFS (median) was 7.7 months with crizotinib and 3.0 months with chemotherapy $(\mathrm{HR}=0.49,95 \% \mathrm{CI}$ $0.37-0.64, P<0.0001)$. PFS (median) with pemetrexed was 4.2 months $(\mathrm{HR}=0.59,95 \% \mathrm{CI} 0.43-0.80, P<0.001$ in favor of crizotinib). PFS with docetaxel was 2.6 months $(\mathrm{HR}=0.30$, $95 \%$ CI $0.21-0.43, P<0.001$ in favor of crizotinib). Response rate was $65 \%$ with crizotinib and $20 \%$ with chemotherapy $(P<0.001)$. OS was similar between the two arms $(\mathrm{HR}=1.02$, 95\% CI 0.67-1.54, $P=0.54$ ) (Table 1). These results allowed the FDA approval in 2011 and the EMA approval in 2012 of crizotinib (250 mg twice daily) for second-line treatment of advanced NSCLC with $A L K$ rearrangement.

\section{Phase III trial PROFILE-I0 I4: crizotinib in first line}

Solomon et al conducted a randomized, open-label, Phase III trial (PROFILE-1014), testing crizotinib in first-line treatment of $A L K$-rearranged advanced NSCLC. ${ }^{16}$ Patients (n=343) with $A L K$-rearranged advanced non-squamous NSCLC (determined by FISH) were randomized between a crizotinib arm (250 mg twice daily, $n=172$ ) and a chemotherapy arm (cisplatin $75 \mathrm{mg} / \mathrm{m}^{2}$ or carboplatin area under the curve (AUC) 5 or 6 , plus pemetrexed $500 \mathrm{mg} / \mathrm{m}^{2}, \mathrm{IV}, \mathrm{d} 1 \mathrm{~d} 21$, up to six cycles, $n=171)$. PS score was $0-2$. Patients with treated brain metastases were eligible if the metastases were neurologically stable for at least 2 weeks before enrollment and if they had no ongoing requirement for glucocorticoids. Crossover was allowed after progression. Primary end point was PFS. PFS (median) was 10.9 months with crizotinib and 7.0 months with chemotherapy $(\mathrm{HR}=0.45,95 \% \mathrm{CI}$ 0.35-0.60, $P<0.001$ ) (Table 1; Figure 1). All prespecified subgroups of patients benefited from crizotinib. Response rate was $74 \%$ with crizotinib and $45 \%$ with chemotherapy $(P<0.001)$. Time to response (median) was 1.4 (crizotinib) and 2.8 months (chemotherapy). Duration of response 
(median) was 11.3 (crizotinib) and 5.3 months (crizotinib). In 109 patients with brain metastases (52 patients in crizotinib arm and 57 patients in chemotherapy arm), the disease control rate at 12 weeks for brain metastases was $65 \%$ with crizotinib versus $46 \%$ with chemotherapy. One-year OS was equivalent in both arms (84\% in crizotinib arm, $79 \%$ in chemotherapy arm), probably due to the crossover. Quality of life was better in the crizotinib arm compared to

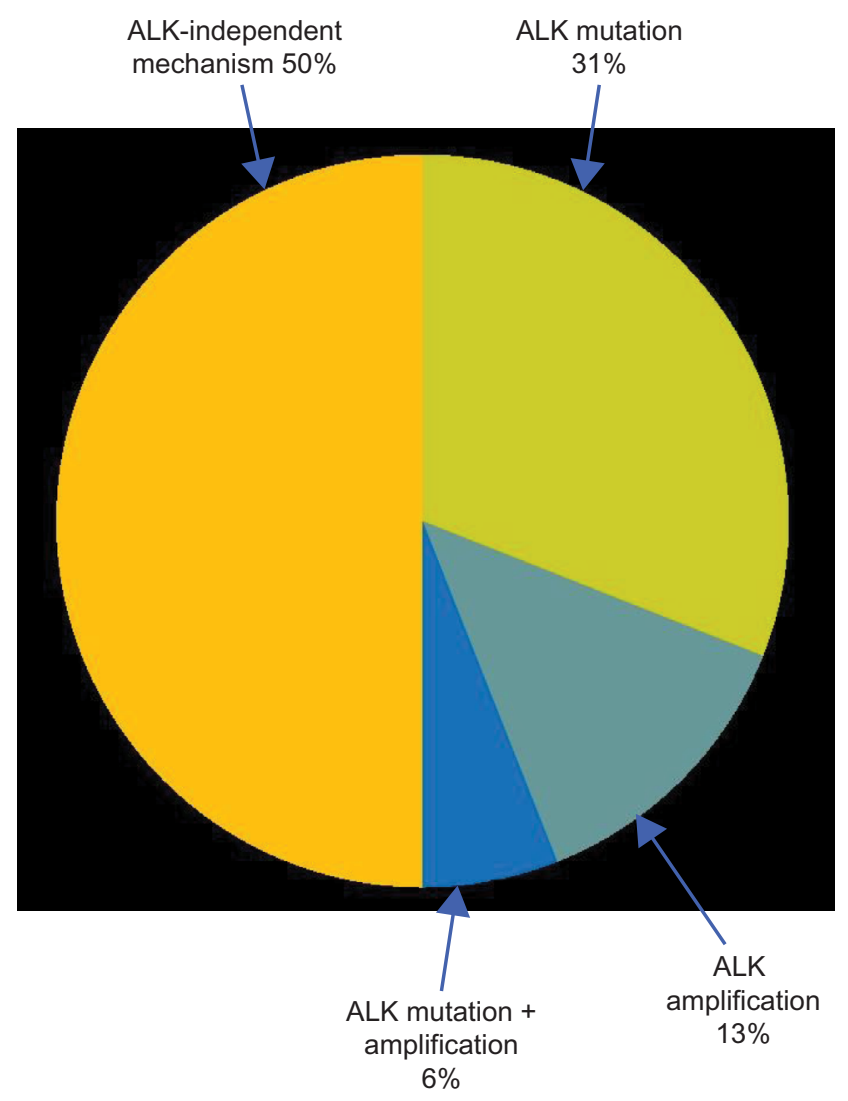

Figure I Mechanisms of acquired resistance to crizotinib. chemotherapy arm. At data-cutoff, $70 \%$ of patients from the chemotherapy arm crossed over to crizotinib arm, and $12 \%$ of the patients from the crizotinib arm subsequently received platinum-based chemotherapy. The very low HR for PFS with crizotinib suggests that the benefit of crizotinib in first line is real and clinically meaningful despite a nonoptimal control arm (no bevacizumab, no maintenance treatment with pemetrexed).

\section{Safety and drug interaction}

Safety results were consistent in all clinical trials (Table 2). Crizotinib was overall well tolerated. In PROFILE-1014, the most frequent side effects were eye disorders $(71 \%)$, diarrhea (61\%), nausea (56\%), peripheral edema (49\%), vomiting (46\%), and constipation (43\%). ${ }^{16}$ Most frequent grade 3-4 side effects were elevated aminotransferases (14\%) and neutropenia (11\%). Grade 3-4 electrocardiogram prolonged QT interval was observed in $2 \%$ of the patients in the crizotinib arm. Fatal pneumonitis occurred in one patient treated with crizotinib (after crossover from chemotherapy arm). Rate of early treatment discontinuation due to side effects was equivalent in crizotinib arm and in chemotherapy arm (12\% and $14 \%$, respectively). Interstitial lung disease, a rare potential severe adverse event, was also reported in the literature. ${ }^{17}$

Administration of crizotinib and inhibitors of the CYP3A induces an augmentation of the plasmatic concentrations of crizotinib. Drugs such as protease inhibitors (atazanavir, indinavir, nelfinavir, ritonavir, saquinavir), some azole-class antifungals (itraconazole, ketoconazole, voriconazole), and some macrolides (clarithromycin, telithromycin, troleandomycin) should be avoided during the treatment with crizotinib.

Table 2 Main adverse events with crizotinib in clinical trials

\begin{tabular}{|c|c|c|c|c|c|c|c|c|}
\hline & \multicolumn{2}{|c|}{ PROFILE- I00I I } & \multicolumn{2}{|c|}{ PROFILE- $1005^{14}$} & \multicolumn{2}{|c|}{ PROFILE- $1007^{15}$} & \multicolumn{2}{|c|}{ PROFILE- $1014^{16}$} \\
\hline & Any grade & Grade 3-4 & Any grade & Grade 3-4 & Any grade & Grade 3-4 & Any grade & Grade 3-4 \\
\hline Vision disorder & 41 & 0 & 52 & 0 & 60 & 0 & 71 & I \\
\hline Diarrhea & 48 & 0 & 41 & I & 60 & 0 & 61 & 2 \\
\hline Nausea & 54 & 0 & 47 & I & 55 & I & 56 & 1 \\
\hline Vomiting & 44 & 0 & 39 & I & 47 & I & 46 & 2 \\
\hline Constipation & 24 & 0 & 28 & 0 & 42 & 2 & 43 & 2 \\
\hline Elevated ALAT/ASAT & 11 & 1 & 28 & 5 & 38 & 16 & 36 & 14 \\
\hline Edema & 16 & 0 & 23 & 0 & 31 & 0 & 49 & 1 \\
\hline Fatigue & 10 & 0 & 18 & 2 & 27 & 2 & 29 & 3 \\
\hline Dysgeusia & 15 & 0 & 17 & 0 & 26 & 0 & 26 & 0 \\
\hline Dizziness & NA & NA & II & 0 & 22 & 1 & 18 & 0 \\
\hline Dyspnea & NA & NA & I & I & 13 & 4 & 18 & 3 \\
\hline Neutropenia & 1 & 0 & 9 & 6 & NA & NA & 21 & 11 \\
\hline Decrease in appetite & 13 & 0 & 19 & 0 & NA & NA & 30 & 2 \\
\hline
\end{tabular}

Notes: Adverse events (\%) listed if they were reported in at least 10\% (PROFILE-I00I and PROFILE-1005) or I5\% (PROFILE-I007 and PROFILE-I0I4) of the patients. Abbreviations: ALAT/ASAT, alanine aminotransferase/aspartate aminotransferase; NA, not available. 
Consumption of grapefruit and grapefruit juice should also be avoided. Inducers of the CYP3A, such as carbamazepin, phenobarbital, phenytoin, rifabutin, rifampicin, and St John's wort, should also be avoided, as they decrease the plasmatic concentration of crizotinib.

\section{Treatment strategy with crizotinib}

Crizotinib received the FDA approval for first-line treatment of $A L K$-rearranged advanced NSCLC in 2013, and the EMA approval for the same indication in November 2015. The question of the best moment to use crizotinib in $A L K$-rearranged NSCLC is relevant. We learned from EGFRmutated NSCLC that first-generation EGFR TKIs (erlotinib, gefitinib) have the same efficacy in first- or second-line treatment. ${ }^{18}$ However, results from the PROFILE trials showed that crizotinib could be more efficient when given in first line compared to subsequent lines. Indeed, response rate was $74 \%$ in PROFILE-1014 (first-line setting) versus 59.8\% in PROFILE-1005 and 65\% in PROFILE-1007 (second-line setting or more). PFS was 10.9 months in PROFILE-1014 (first-line setting) versus 7.7 months in PROFILE-1007 (second-line setting or more). Even if the comparison between different trials is subject to caution, these differences encourage to screen advanced NSCLC for ALK status at the diagnosis, and to use crizotinib in first-line treatment, when it is possible.

\section{Mechanisms of resistance to crizotinib}

Despite great response rate, $A L K$-rearranged NSCLC progresses under crizotinib after 8-12 months. The tumor progression occurs notably in the brain. Crizotinib is a substrate of the PgP, which is a membranous transporter overexpressed in the hemato-encephalic barrier and responsible for the efflux of the drug. This pharmacological specificity could explain that around half of the patients treated with crizotinib will have a cerebral progression.

Several cellular and molecular resistance mechanisms have been described so far to explain secondary resistance to crizotinib (Figure 2). ${ }^{19}$ In half of the cases, the resistance mechanism is ALK dependent ( $A L K$ amplification and/or $A L K$ mutation). Known $A L K$ mutations that cause resistance to crizotinib are L1196M, C1156Y, F1174L, G1269A, 1151Tins, L1152R, S1206Y, I1 171T, V1180L, D1203N, and G1202R. ${ }^{20}$ The other half of the resistance cases concern ALK-independent mechanisms, such as EGFR or Kras pathway activation. Among eleven patients with $A L K$-rearranged NSCLC treated with crizotinib, one patient ( $9 \%$ ) harbored an EGFR mutation, and two patients, a Kras mutation (18\%) at the time of progression. ${ }^{21}$ HER2 activation has also been involved in acquired resistance to crizotinib. ${ }^{19}$ An analysis of nine cases of crizotinib progression showed the apparition of a phosphorylation of HER2 in four cases (44\%). Other mechanisms, such as Kit amplification ${ }^{19}$ or IGF1R pathway activation, ${ }^{22}$ have also been described. However, except acquired EGFR mutation that opens the possibility of targeted EGFR TKI treatment, the clinical implications of the other ALK-independent mechanisms of crizotinib resistance need to be clarified. It is also important to notice that all these mechanisms have been described in a very limited number of patients. Larger cohorts of patients with documented molecular status at the time of progression are therefore needed.

\section{Treatment strategies beyond progression}

Recently, new ALK TKIs have been developed to overcome resistance to crizotinib, such as ceritinib, alectinib, and lorlatinib. After failure of crizotinib, response rates are high, 58\% with ceritinib ${ }^{23}$ and $50 \%$ with alectinib, ${ }^{24}$ including efficacy in brain metastases. As discussed, acquired $A L K$ mutations can be responsible for crizotinib progression. Interestingly, some of these mutations seem to induce different sensitivity to second-generation ALK inhibitors. For example, I1171T mutation, associated with crizotinib resistance, is also associated with resistance to alectinib. C1156Y and L1152R mutations also induce resistance to ceritinib. G1202R mutation seems to induce resistance to crizotinib, alectinib, and ceritinib. A recent report also described a patient with an acquired resistance mutation with crizotinib (C1156Y), who developed another ALK mutation under lorlatinib (L1198F) in addition to the $\mathrm{C} 1156 \mathrm{Y}$ mutation. ${ }^{25} \mathrm{~L} 1198 \mathrm{~F}$ mutation is associated with resistance to lorlatinib but confers sensitivity to crizotinib. This patient received again crizotinib with a good tumor response. New molecular screening at the time of progression under crizotinib, through re-biopsy or circulating plasmatic DNA analysis, is therefore advised to guide the best choice of second-generation ALK inhibitor. ${ }^{26}$ Several questions remain concerning the best treatment sequence. Is there an interest for second-generation ALK inhibitors in firstline treatment? The potential addition of PFS with crizotinib and then ceritinib or alectinib could argue for a prescription of these new drugs after failure of crizotinib. However, clinical trials with specific design are needed to answer this question. An ongoing randomized Phase III trial (ALEX study, NCT02075840), comparing alectinib and crizotinib in treatment-naive ALK-positive advanced NSCLC, may 


\section{Progression-free survival}

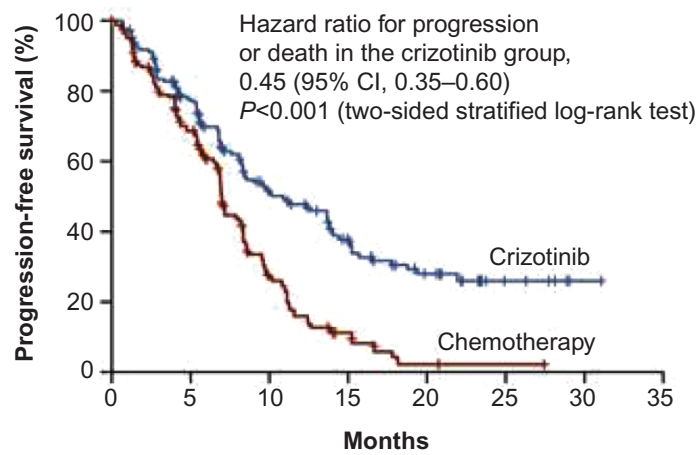

Number at risk

$\begin{array}{lllllllll}\text { Crizotinib } & 172 & 120 & 65 & 38 & 19 & 7 & 1 & 0\end{array}$

$\begin{array}{lllllllll}\text { Chemotherapy } & 171 & 105 & 36 & 12 & 2 & 1 & 0 & 0\end{array}$

Figure 2 Progression-free survival results of PROFILE-1014.

partially answer this question. Moreover, the conventional chemotherapy plays a major role in $A L K$-rearranged NSCLCs as these tumors have a high sensitivity to pemetrexed. ${ }^{27}$

The best treatment strategy at the time of progression under crizotinib depends on the profile of progression. A retrospective analysis of patients included in crizotinib-based clinical trials who had tumor progression according to RECIST $(n=194)$ showed that, in patients who continued crizotinib beyond progression because of clinical benefit, OS was longer than in patients who stopped crizotinib (median 29.6 versus 10.8 months; HR $=0.30,95 \% \mathrm{CI}$ : $0.19-0.46, P<0.0001) .{ }^{28} \mathrm{PS}$ was better $(0 / 1)$ in $96 \%$ versus $82 \%$ of patients $(P=0.02)$, respectively. This retrospective non-randomized analysis does not allow definitive conclusions on the best management at the time of progression under crizotinib but suggests that some patients could benefit from the continuation of crizotinib beyond progression. More likely, patients with slow, oligometastatic progression could be subjected to localized treatment on progression sites, with continuation of crizotinib. Especially, brain progression occurs in around half of the patients under crizotinib, mainly because of poor brain penetration of crizotinib. For low number of symptomatic brain metastases, without extra-brain progression, a local treatment (stereotactic radiotherapy, surgery) could be proposed, with treatment with ALK TKIs (continuation with crizotinib or switch to a second-generation ALK inhibitor). ${ }^{29}$ Whole-brain radiotherapy is another option for the treatment of brain metastases, but results in neurocognitive impairment, and should be reserved for extensive symptomatic brain metastases. Small asymptomatic brain metastases should be followed up, or a switch to a second-generation ALK inhibitor should be proposed. For extensive poly-visceral progression under crizotinib, a switch to a second-generation
ALK inhibitor or systemic pemetrexed-based chemotherapy should be proposed.

Overall, patients with $A L K$-rearranged advanced NSCLC, who can access sequential crizotinib and second-generation ALK inhibitor treatment, have a prolonged OS, exceeding 4 years. ${ }^{30}$ This long survival, unusual in advanced NSCLC, should be a key component in the treatment decisions for ALK-rearranged NSCLC, with priority given to local treatments on progression sites when possible, and favoring strategies with low-grade side effects.

\section{Conclusion}

Although $A L K$ rearrangement is a rare molecular feature in advanced NSCLC, the possibility to use high-efficiency targeted therapies, such as crizotinib, is a major advance and a real improvement in the management of this kind of tumor. The presence of an $A L K$ rearrangement fulfills all the criteria for an oncogenic addiction, notably with a high response rate and durable tumor response with crizotinib. Based on the different results of the PROFILE trials, the best strategy is to use crizotinib in first-line setting, with probably a higher efficiency compared to subsequent lines. The best option at the time of the progression remains undefined, and the choice between crizotinib beyond progression, local treatment on the progression site, switch to a next-generation ALK TKI, or systemic pemetrexed-based chemotherapy is based on the phenotype of the tumor progression, on the molecular profile of the tumor at the time of the progression (re-biopsy), and on the physical condition of the patient at the progression. Further clinical trials are warranted to answer these questions.

\section{Disclosure}

The authors report no conflicts of interest in this work.

\section{References}

1. Schiller JH, Harrington D, Belani CP, et al. Comparison of four chemotherapy regimens for advanced non-small-cell lung cancer. $N$ Engl J Med. 2002;346(2):92-98.

2. Scagliotti GV, Parikh P, von Pawel J, et al. Phase III study comparing cisplatin plus gemcitabine with cisplatin plus pemetrexed in chemotherapy-naive patients with advanced-stage non-small-cell lung cancer. J Clin Oncol. 2008;26(21):3543-3551.

3. Barlesi F, Mazieres J, Merlio J-P, et al. Routine molecular profiling of patients with advanced non-small-cell lung cancer: results of a 1-year nationwide programme of the French Cooperative Thoracic Intergroup (IFCT). Lancet. 2016;387(10026):1415-1426.

4. Soda M, Choi YL, Enomoto M, et al. Identification of the transforming EML4-ALK fusion gene in non-small-cell lung cancer. Nature. 2007;448(7153):561-566

5. Shaw AT, Yeap BY, Mino-Kenudson M, et al. Clinical features and outcome of patients with non-small-cell lung cancer who harbor EML4ALK. J Clin Oncol. 2009;27(26):4247-4253. 
6. Fallet V, Cadranel J, Doubre H, et al. Prospective screening for ALK: clinical features and outcome according to ALK status. Eur J Cancer. 2014;50(7):1239-1246.

7. Won JK, Keam B, Koh J, et al. Concomitant ALK translocation and EGFR mutation in lung cancer: a comparison of direct sequencing and sensitive assays and the impact on responsiveness to tyrosine kinase inhibitor. Ann Oncol. 2015;26(2):348-354.

8. McLeer-Florin A, Moro-Sibilot D, Melis A, et al. Dual IHC and FISH testing for ALK gene rearrangement in lung adenocarcinomas in a routine practice: a French study. J Thorac Oncol. 2012;7(2):348-354.

9. Wang Y, Zhang J, Gao G, et al. EML4-ALK fusion detected by RT-PCR confers similar response to crizotinib as detected by FISH in patients with advanced non-small-cell lung cancer. JThorac Oncol. 2015;10(11): 1546-1552.

10. McDermott U, Iafrate AJ, Gray NS, et al. Genomic alterations of anaplastic lymphoma kinase may sensitize tumors to anaplastic lymphoma kinase inhibitors. Cancer Res. 2008;68(9):3389-3395.

11. Kwak EL, Bang Y-J, Camidge DR, et al. Anaplastic lymphoma kinase inhibition in non-small-cell lung cancer. $N$ Engl J Med. 2010;363(18):1693-1703.

12. Shaw AT, Yeap BY, Solomon BJ, et al. Effect of crizotinib on overall survival in patients with advanced non-small-cell lung cancer harbouring ALK gene rearrangement: a retrospective analysis. Lancet Oncol. 2011;12(11):1004-1012.

13. Camidge DR, Bang Y-J, Kwak EL, et al. Activity and safety of crizotinib in patients with ALK-positive non-small-cell lung cancer: updated results from a phase 1 study. Lancet Oncol. 2012;13(10):1011-1019.

14. Kim DW, Ahn M-J, Shi Y, et al. Results of a global phase II study with crizotinib in advanced ALK-positive non-small cell lung cancer (NSCLC). J Clin Oncol. 2012;30(Suppl):abstr 7533.

15. Shaw AT, Kim D-W, Nakagawa K, et al. Crizotinib versus chemotherapy in advanced ALK-positive lung cancer. $N$ Engl J Med. 2013;368(25):2385-2394.

16. Solomon BJ, Mok T, Kim D-W, et al. First-line crizotinib versus chemotherapy in ALK-positive lung cancer. NEngl JMed. 2014;371(23):2167-2177.

17. Créquit P, Wislez M, Fleury Feith J, et al. Crizotinib associated with groundglass opacity predominant pattern interstitial lung disease: a retrospective observational cohort study with a systematic literature review. J Thorac Oncol. 2015;10(8):1148-1155.
18. Rosell R, Moran T, Queralt C, et al. Screening for epidermal growth factor receptor mutations in lung cancer. $N$ Engl J Med. 2009;361(10): 958-967.

19. Katayama R, Shaw AT, Khan TM, et al. Mechanisms of acquired crizotinib resistance in ALK-rearranged lung cancers. Sci Transl Med. 2012;4(120):120ra17.

20. Toyokawa G, Seto T. Updated evidence on the mechanisms of resistance to ALK inhibitors and strategies to overcome such resistance: clinical and preclinical data. Oncol Res Treat. 2015;38(6):291-298.

21. Doebele RC, Pilling AB, Aisner DL, et al. Mechanisms of resistance to crizotinib in patients with ALK gene rearranged non-small cell lung cancer. Clin Cancer Res. 2012;18(5):1472-1482.

22. Lovly CM, McDonald NT, Chen H, et al. Rationale for co-targeting IGF-1R and ALK in ALK fusion-positive lung cancer. Nat Med. 2014;20(9):1027-1034.

23. Shaw AT, Kim D-W, Mehra R, et al. Ceritinib in ALK-rearranged nonsmall-cell lung cancer. N Engl J Med. 2014;370(13):1189-1197.

24. Ou S-HI, Ahn JS, De Petris L, et al. Alectinib in crizotinib-refractory ALK-rearranged non-small-cell lung cancer: a phase II global study. J Clin Oncol. 2016;34(7):661-668.

25. Shaw AT, Friboulet L, Leshchiner I, et al. Resensitization to crizotinib by the lorlatinib ALK resistance mutation L1198F. $N$ Engl J Med 2016;374(1):54-61.

26. Bosc C, Ferretti GR, Cadranel J, et al. Rebiopsy during disease progression in patients treated by TKI for oncogene-addicted NSCLC. Target Oncol. 2015;10(2):247-253.

27. Park S, Park TS, Choi C-M, et al. Survival benefit of pemetrexed in lung adenocarcinoma patients with anaplastic lymphoma kinase gene rearrangements. Clin Lung Cancer. 2015;16(5):e83-e89.

28. Ou S-HI, Jänne PA, Bartlett $\mathrm{CH}$, et al. Clinical benefit of continuing ALK inhibition with crizotinib beyond initial disease progression in patients with advanced ALK-positive NSCLC. Ann Oncol. 2014;25(2):415-422.

29. Johung KL, Yeh N, Desai NB, et al. Extended survival and prognostic factors for patients with ALK-rearranged non-small-cell lung cancer and brain metastasis. J Clin Oncol. 2016;34(2):123-129.

30. Gainor JF, Tan DSW, De Pas T, et al. Progression-free and overall survival in ALK-positive NSCLC patients treated with sequential crizotinib and ceritinib. Clin Cancer Res. 2015;21(12):2745-2752. 


\section{Publish your work in this journal}

Lung Cancer: Targets and Therapy is an international, peer-reviewed, open access journal focusing on lung cancer research, identification of therapeutic targets and the optimal use of preventative and integrated treatment interventions to achieve improved outcomes, enhanced survival and quality of life for the cancer patient. Specific topics covered in the journal include: Epidemiology, detection and screening; Cellular research and biomarkers; Identification of biotargets and agents with novel published authors.

mechanisms of action; Optimal clinical use of existing anticancer agents, including combination therapies; Radiation and surgery; Palliative care; Patient adherence, quality of life, satisfaction; Health economic evaluations. The manuscript management system is completely online and includes a very quick and fair peer-review system. Visit http://www.dovepress.com/testimonials.php to read real quotes from

Submit your manuscript here: https://www.dovepress.com/lung-cancer-targets--therapy-journal 